\title{
Machine Learning modeling techniques for forecasting the trophic level in a restored South Mediterranean lagoon using Chlorophyll-a
}

Nadia Ben Hadid ( $\square$ nadiabenhadid01@gmail.com )

Universite de Perpignan Via Domitia: Universite de Perpignan https://orcid.org/0000-0003-2318-7624

Catherine Goyet

Universite de Perpignan Via Domitia: Universite de Perpignan

Hatem Chaar

Institut National Agronomique de Tunis

Naceur Ben Maiz

Société de Promotion du Lac de Tunis

Veronique Guglielmi

Universite de Perpignan Via Domitia: Universite de Perpignan

Abdessalem Shili

Institut National Agronomique de Tunis

\section{Research Article}

Keywords: Machine Learning, NARX, Random Forest, Eutrophication, North Lagoon of Tunis, Forecasting

Posted Date: March 26th, 2021

DOl: https://doi.org/10.21203/rs.3.rs-331963/v1

License: (9) (i) This work is licensed under a Creative Commons Attribution 4.0 International License.

Read Full License

Version of Record: A version of this preprint was published at Wetlands on November 16th, 2021. See the published version at https://doi.org/10.1007/s13157-021-01479-6. 


\section{Abstract}

An Artificial Neural Network (ANN), a Machine Learning (ML) modeling approach is proposed to predict the ecological state of the North Lagoon of Tunis, a shallow restored Mediterranean coastal ecosystem. A Nonlinear Auto Regressive with exogenous input (NARX) neural network model was fitted to predict Chlorophyll- a (Chl- a ) concentrations in the North Lagoon of Tunis as an eutrophication indicator. The modeling is based on approximately three decades of monitoring water quality data (from January 1989 to April 2018) to train, validate and test the NARX model. The most relevant predictor variables used in this model were those having a high permutation importance ranking with Random Forest (RF) model, which simplified the structure of the network, resulting in a more accurate and efficient procedure. Those predictor variables are secchi depth, and dissolved oxygen. Various model scenarios with different NARX architectures were tested for Chl- a prediction. To verify the model performances, the trained models were applied to field monitoring data. Results indicated that the developed NARX model can predict Chl- a concentrations in the North Lagoon of Tunis with high accuracy $(R=0.79 ; M S E=0.31)$. In addition, results showed that the NARX model generally performed better than multivariate linear regression (MVLR). This approach could provide a quick assessment of Chl- a variations for lagoon management and ecorestoration.

\section{Full-text}

Due to technical limitations, full-text HTML conversion of this manuscript could not be completed. However, the manuscript can be downloaded and accessed as a PDF.

\section{Figures}



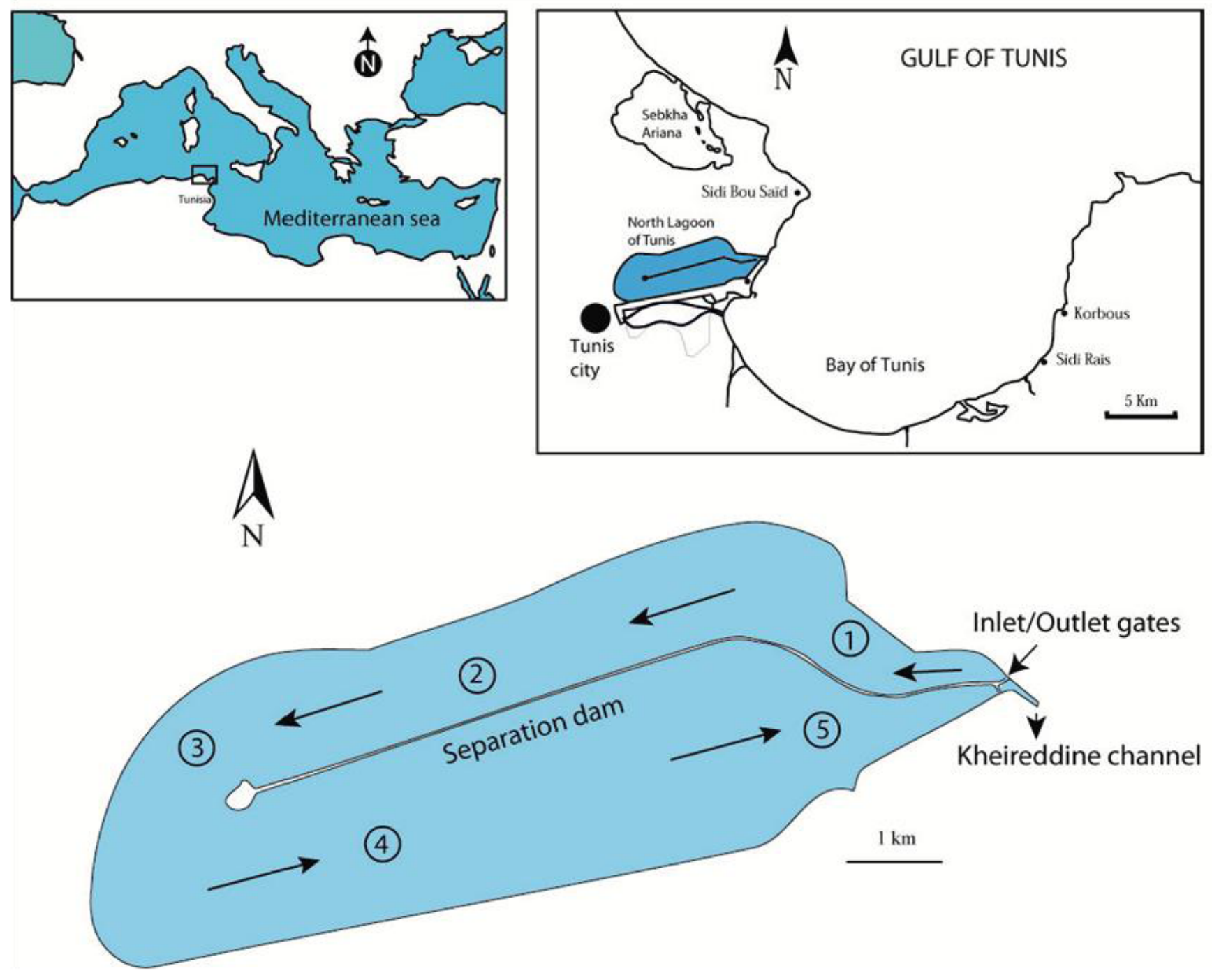

Figure 1

Location of the study area and water quality monitoring stations (1-5). Arrows inside the map represent the unidirectional inlet/outlet water circulation system. 


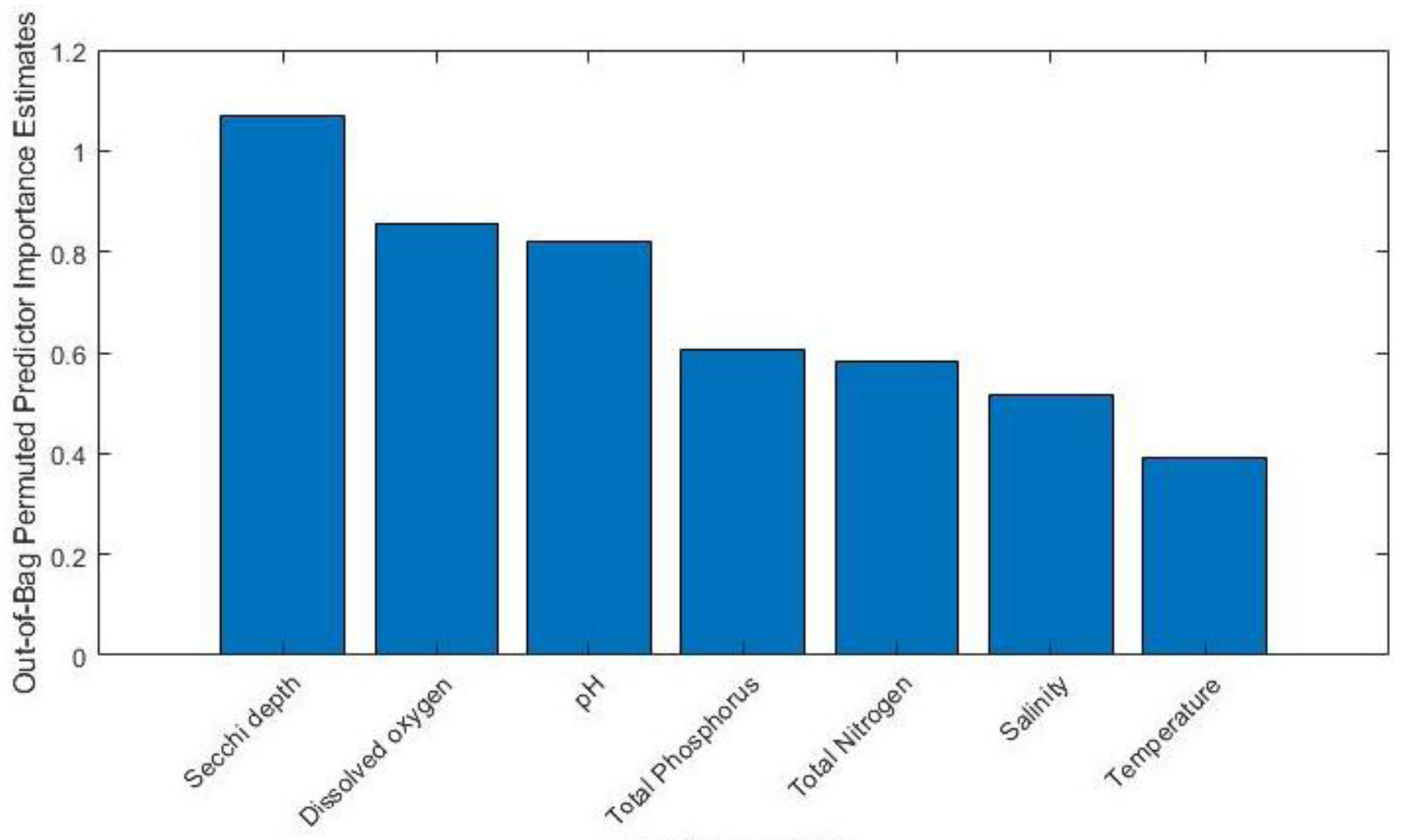

Predictor variable

Figure 2

Predictors importance ranking for the "first" RF model to predict Chl-a content in the North Lagoon of Tunis. The importance of each predictor is measured using the $\mathrm{OOB}$ technique by permutation due to each predictor. 


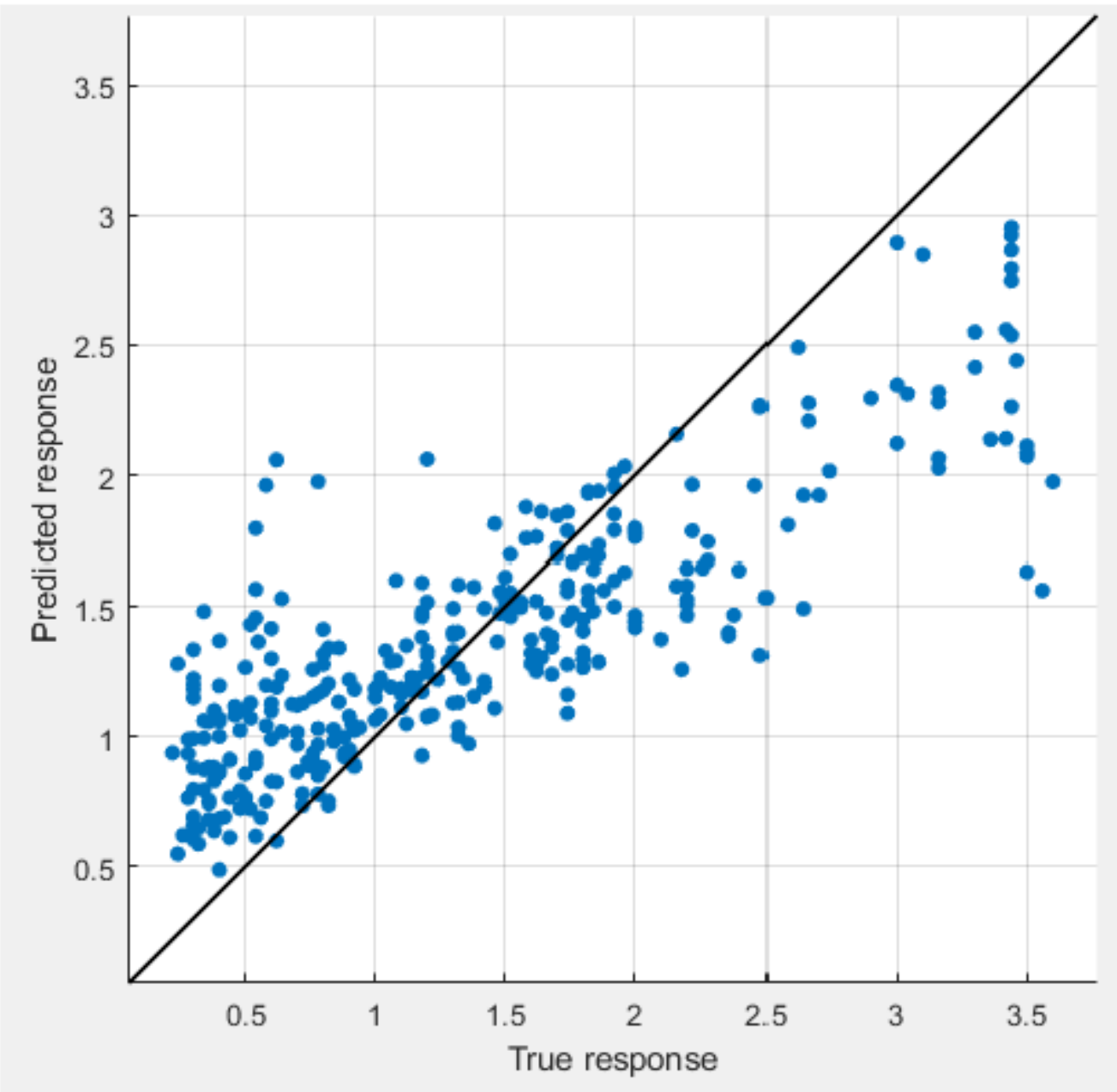

Figure 3

RF Prediction of the Chl-a concentrations using the physicochemical predictor variables data in the North Lagoon of Tunis. Predicted response is Predicted Chl-a values and True response is Observed Ch-a values. 


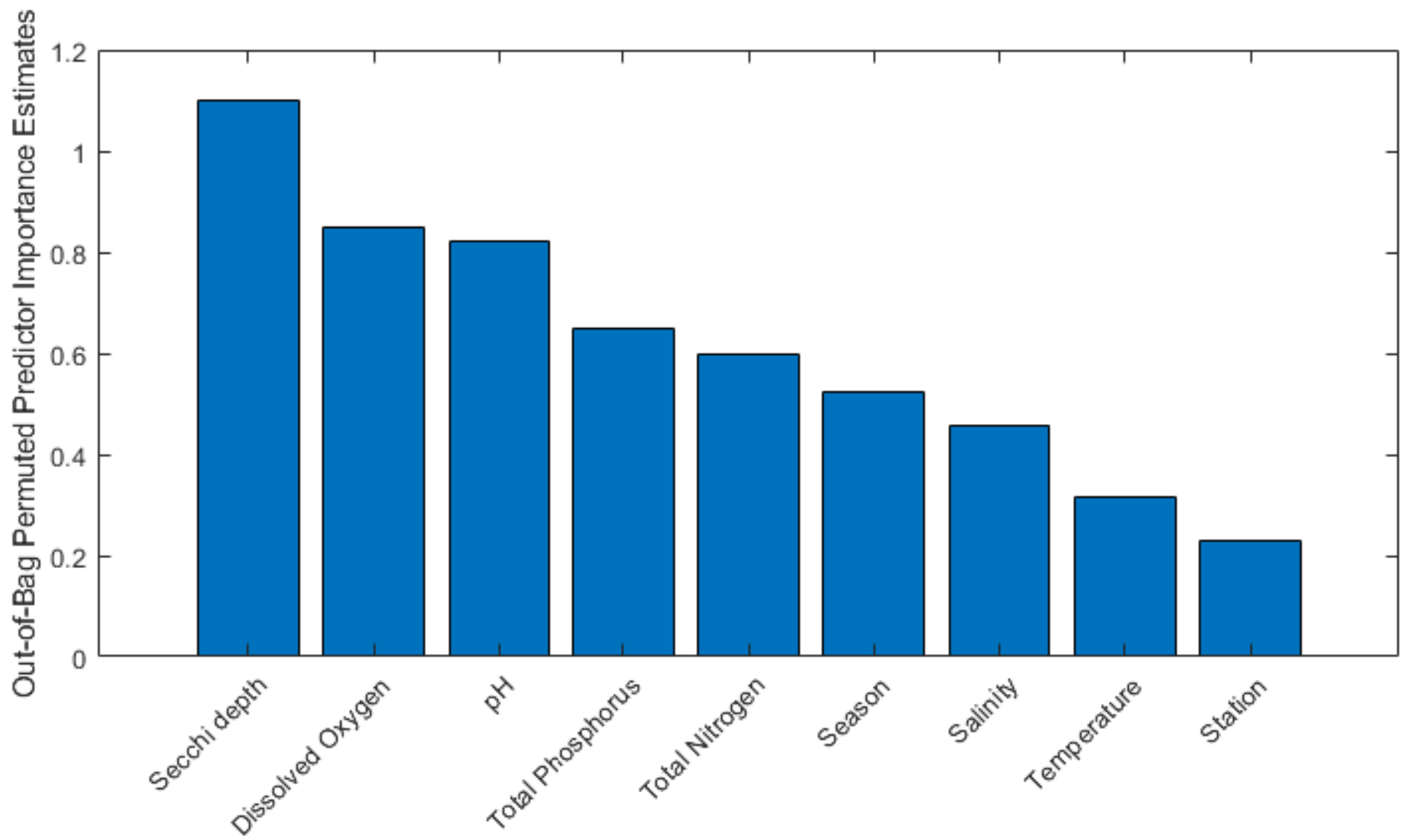

Predictor variable

\section{Figure 4}

Predictor importance ranking for the "second" RF model to predict Chl-a content in the North Lagoon of Tunis. The importance of each predictor is measured using the $\mathrm{OOB}$ technique by permutation due to each predictor. 


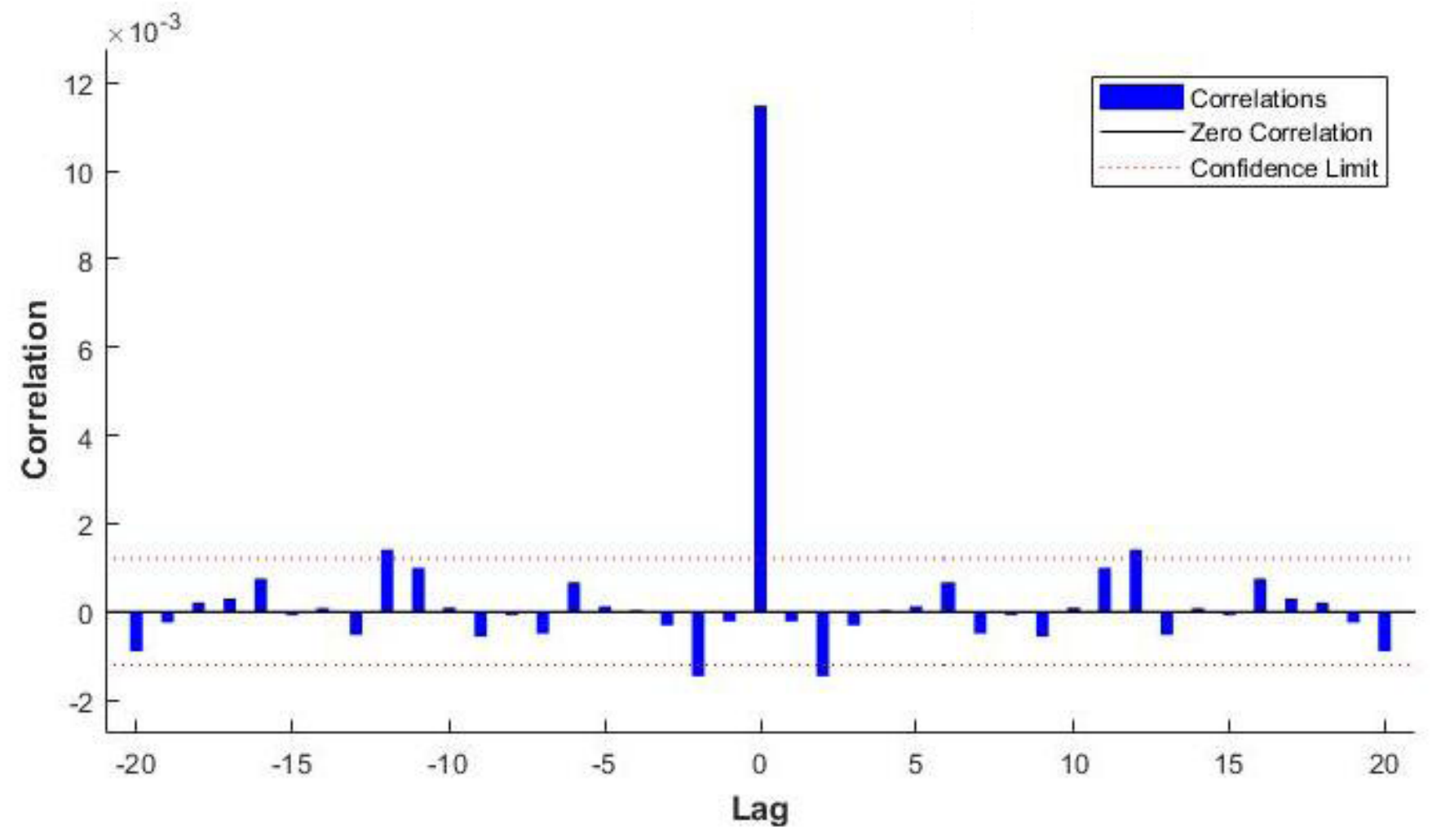

Figure 5

The autocorrelation error plot.

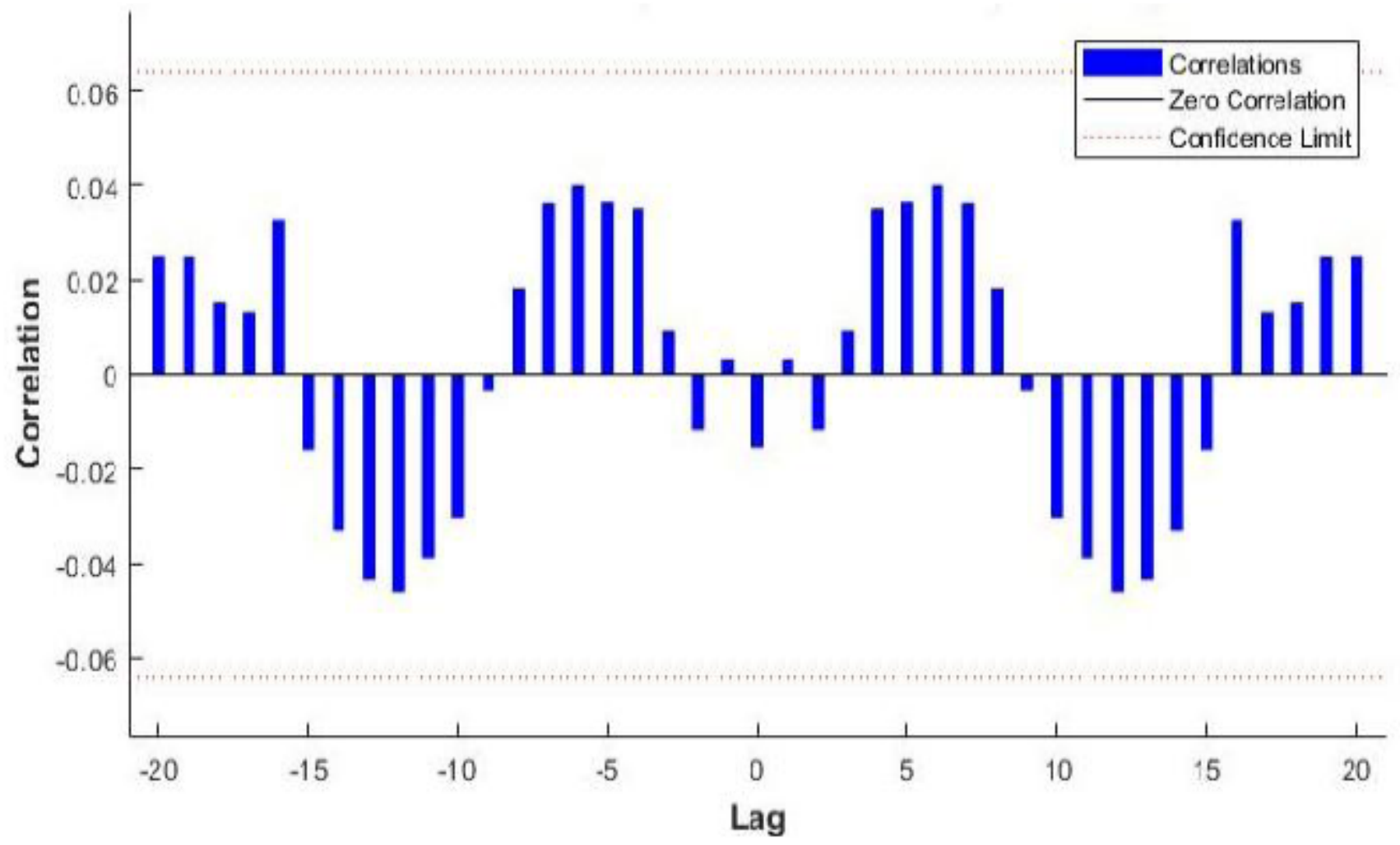


Figure 6

The input-error cross-correlation plot.
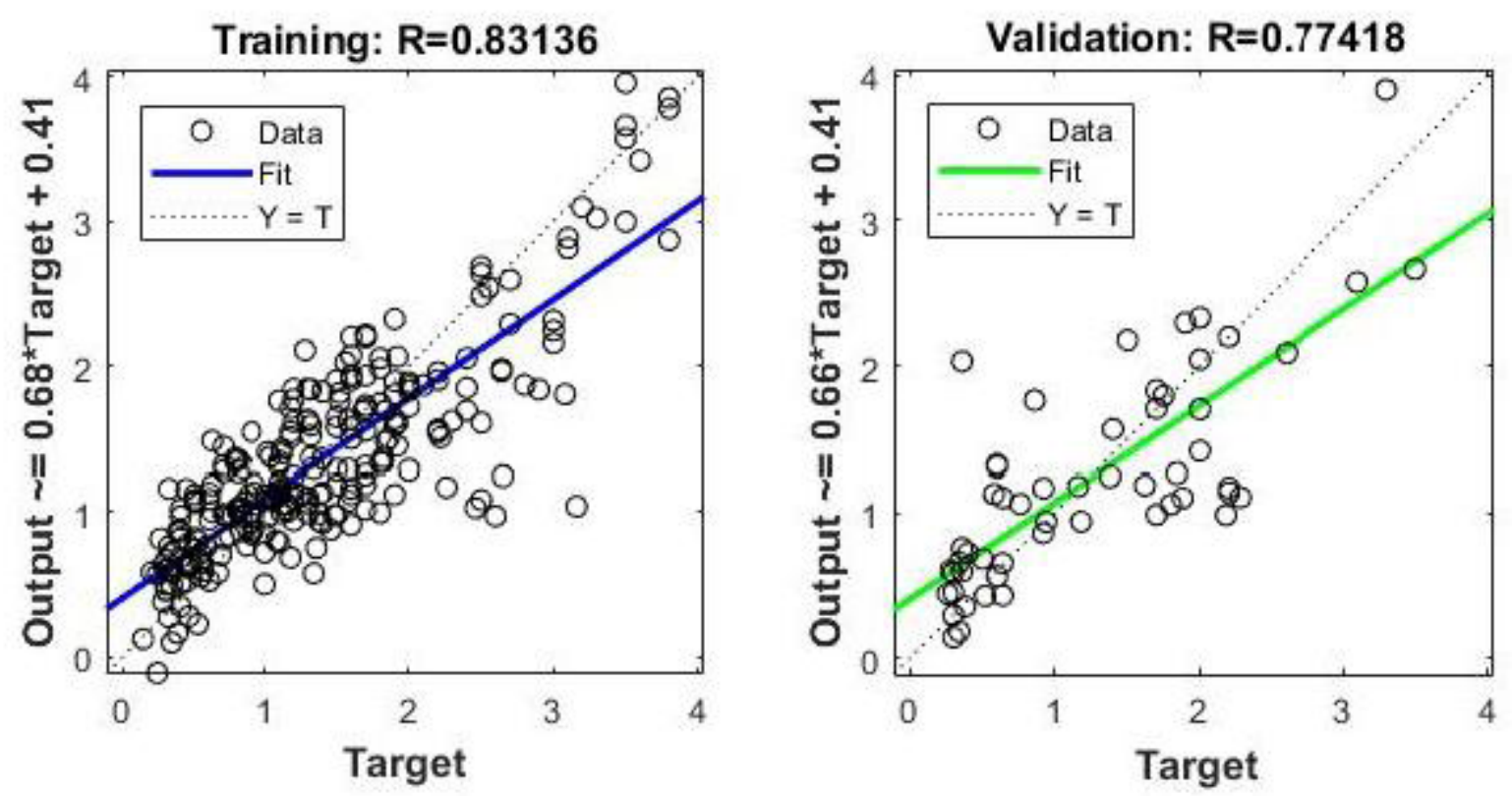

Test: $\mathbf{R}=\mathbf{0 . 6 0 5 3 9}$
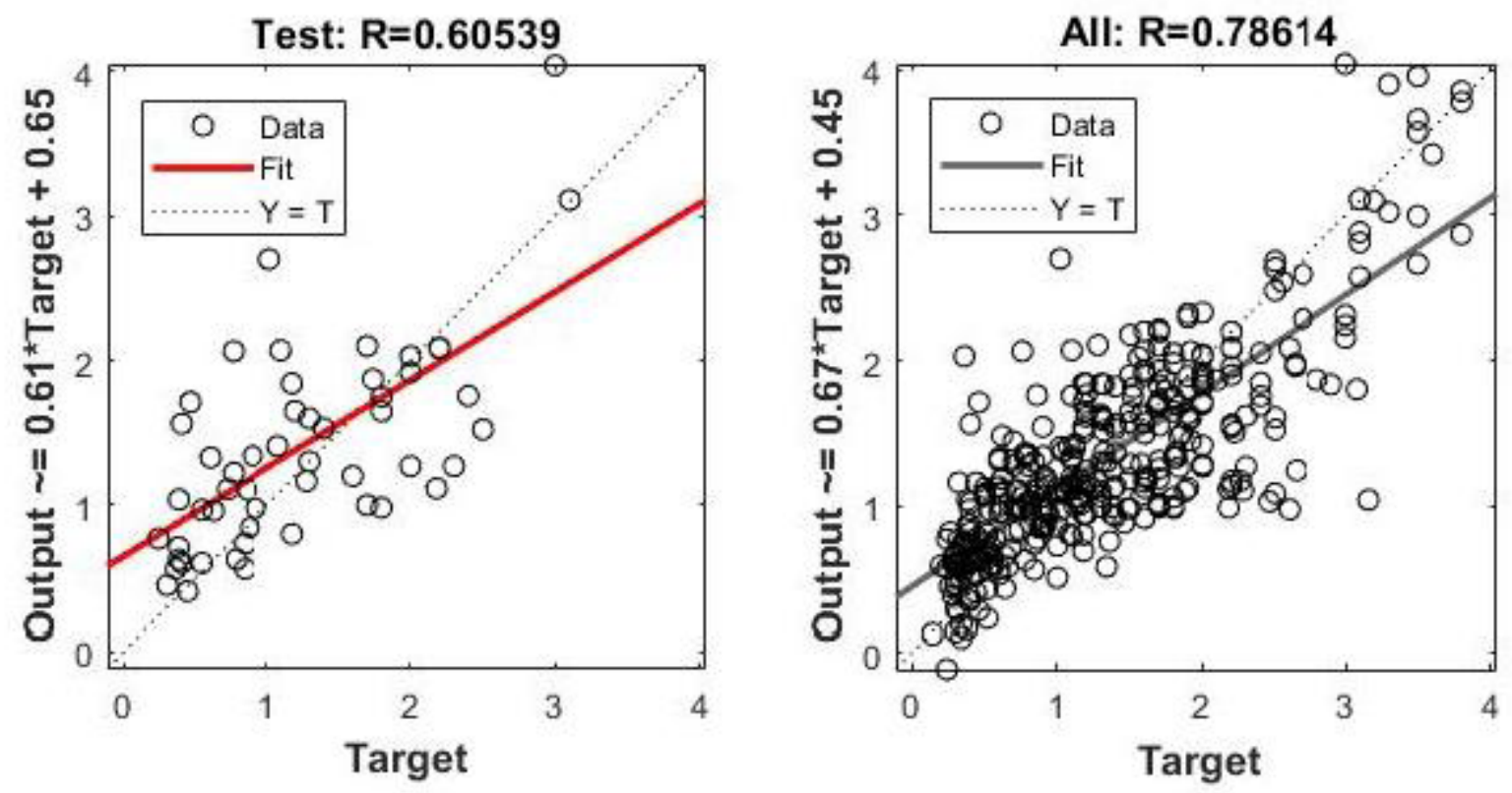

Figure 7

Correlation between original (target) and predicted (output) Chl-a values obtained with the NARX network 


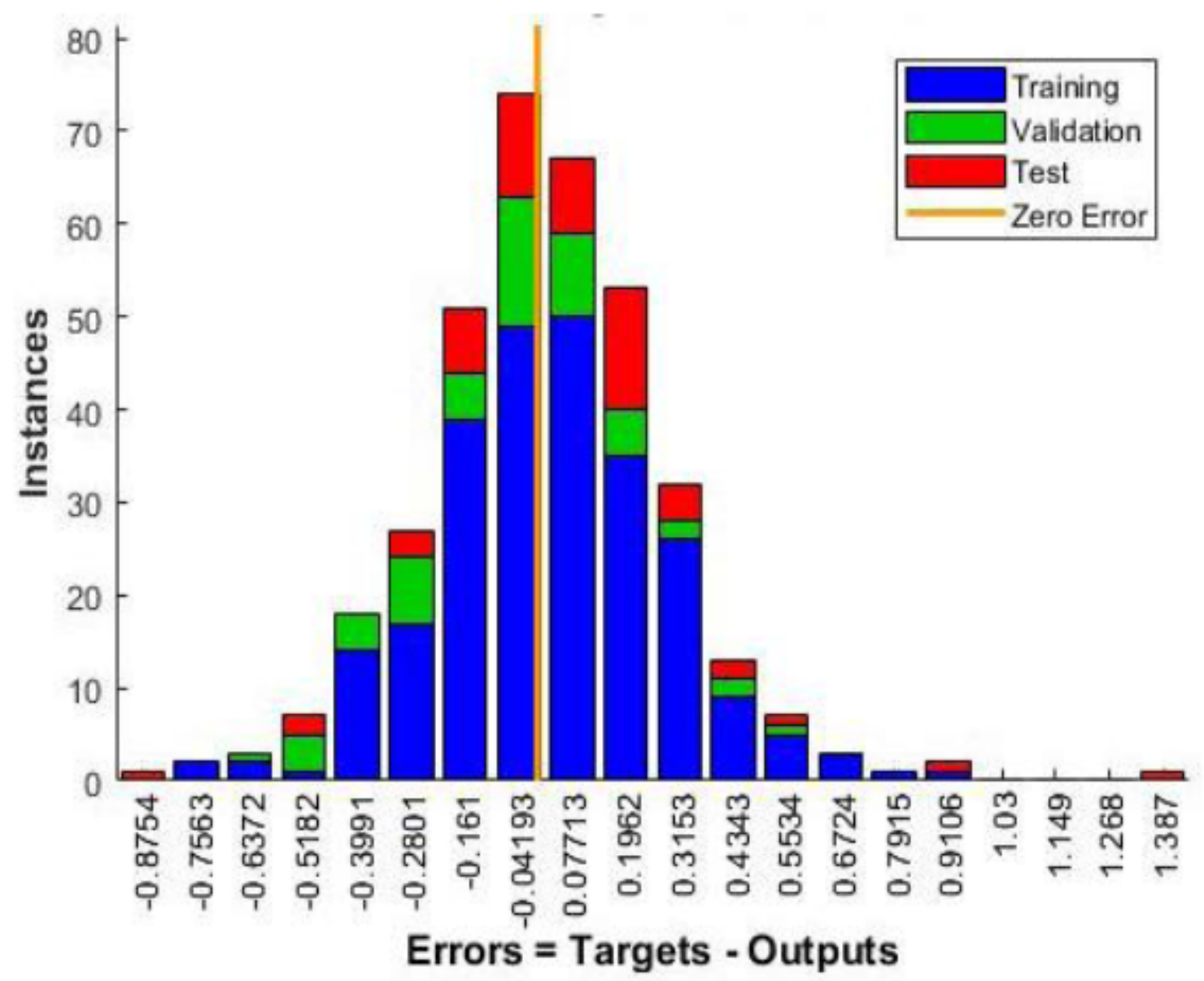

Figure 8

Error histogram of the NARX network. 


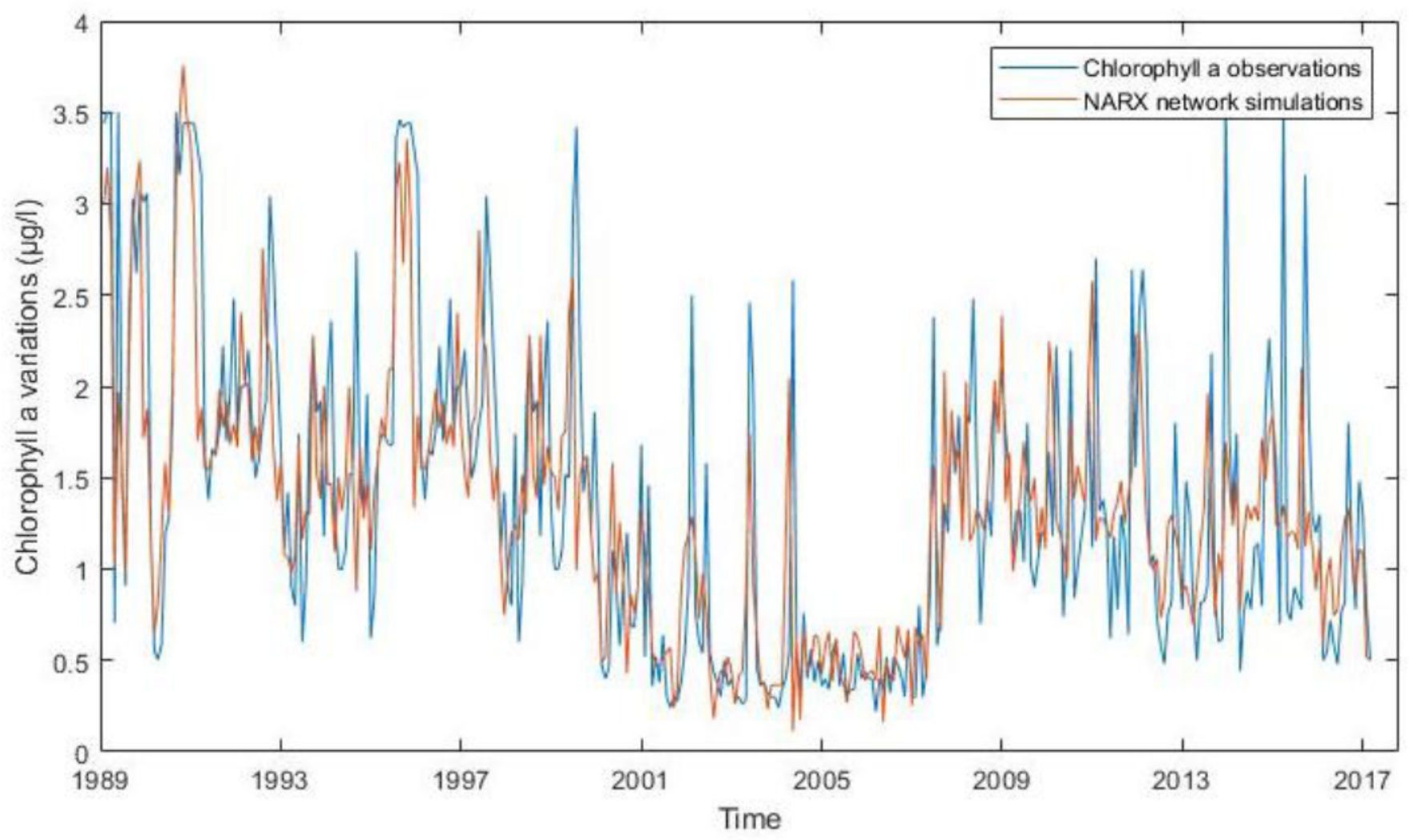

Figure 9

Observed and modeled Chl-a concentrations using NARX network in the North Lagoon of Tunis. 